\title{
Ileal Neuroendocrine Tumor by AJCC v8 Stage
}

National Cancer Institute

\section{Source}

National Cancer Institute. Ileal Neuroendocrine Tumor by AJCC v8 Stage. NCI Thesaurus. Code C135124.

A term that refers to the staging of an ileal neuroendocrine tumor, following the rules of the TNM AJCC v8 classification system. This classification system applies to small bowel "carcinoid" tumors (NET G1 and G2, and rare well-differentiated G3) arising in the ileum. This classification system does not apply to high-grade neuroendocrine carcinomas, mixed adenoneuroendocrine carcinomas, and neuroendocrine tumors of the duodenum. (from AJCC 8th Ed.) 